\title{
Air bubbles in the rectus abdominis muscle
}

\author{
Alberto Cereda, ${ }^{1}$ Paolo Aseni, ${ }^{2}$ Marco Cereda,,${ }^{1}$ Maurizio Vertemati ${ }^{3}$ \\ ${ }^{1}$ Cardiovascular Department, Niguarda Ca' Granda Hospital; ${ }^{2}$ Department of General Surgery and Abdominal Organ \\ Transplantation, Niguarda Ca' Granda Hospital; ${ }^{3}$ Department of Biomedical and Clinical Sciences, Luigi Sacco Hospital, \\ Milano, Italy
}

\section{Imaging in Internal Medicine}

Abnormal gas presented as small air bubbles can be a great concern for surgeons suggesting abscess or necrotizing soft tissue infection. A 73-year-old woman with known bronchiectasis was admitted to our institute complaining of fever and dyspnoea. A diagnosis of multilobar pneumonia was made based on clinical findings and chest X-ray. Broad-spectrum antibiotic therapy and low-molecular-weight heparins (LMWHs) for deep vein thrombosis were administered. The patient developed diarrhoea and abdominal tenderness with mild increase in leucocytes and blood lactate. An abdominal computed tomography (CT)-scan did not show abnormal findings with the exception of small air bubbles in the right rectus abdominis (Figure $1 \mathrm{~A}$ and $\mathrm{B}$, arrowheads). Antibiotic-associated diarrhoea was diagnosed without pseudo-membranous colitis; the diagnosis was confirmed by its resolution after suspension of an-

Correspondence: Alberto Cereda, Cardiovascular Department, Niguarda Hospital, Piazza dell'Ospedale Maggiore 3, 20162 Milano, Italy.

Tel.: +39.02.6444.1 - Fax: +39.02.6420901.

E-mail: alberto.cereda@email.it

Key words: Air bubbles; prefilled heparin syringes; lowmolecular-weight heparins; rectus abdominis.

Conflict of interest: the authors declare no potential conflict of interest.

Received for publication: 22 August 2015.

Revision received: 29 November 2016.

Accepted for publication: 3 January 2017.

This work is licensed under a Creative Commons Attribution NonCommercial 4.0 License (CC BY-NC 4.0).

CCopyright A. Cereda et al., 2017

Licensee PAGEPress, Italy

Italian Journal of Medicine 2017; 11:343

doi:10.4081/itjm.2017.638 tibiotics. The patient recovered completely shortly after the discontinuation of antibiotics. Rectus abdominis, as reported in medical literature, could be the site of iatrogenic injury such as hematomas related to subcutaneous heparin injection and its involvement may always assume an iatrogenic cause. In the package leaflet of LMWHs, it is recommended not to remove air bubbles from the prefilled syringe to avoid expelling some of the drug. The equivocal finding on the CT-scan was caused by air bubbles contained in the prefilled syringe of LMWH and accidently injected into the muscle because of the thin layer of subcutaneous fat tissue.
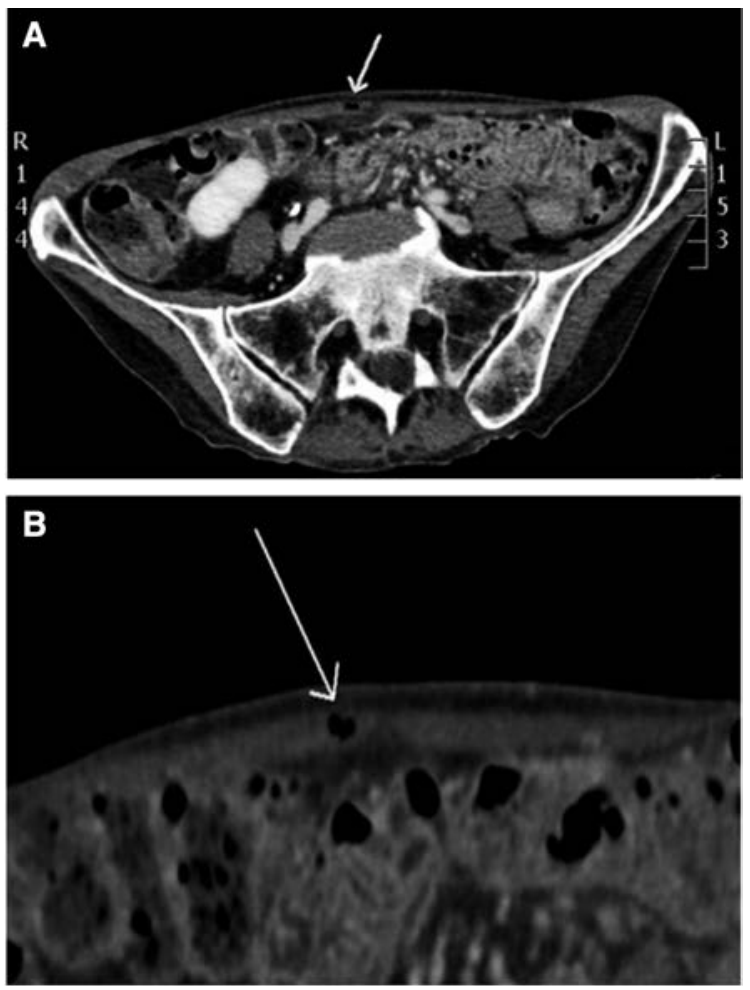

Figure 1. A) Abdominal computed tomography of the lower abdomen. Unexplained air bubbles in the rectus abdomins muscle; B) Air bubbles in the rectus abdominis. 